Citation: G. Cappuccio, G. Compagno (2021) Developing supportteachers'digital competencies for an inclusive citizenship. Media Education 12(1): 43-51. doi: 10.36253/me-10243

Received: December, 2020

Accepted: March, 2021

Published: May, 2021

Copyright:@2021 G. Cappuccio, G. Compagno. This is an open access, peerreviewed article published by Firenze University Press (http://www.fupress. $\mathrm{com} / \mathrm{me}$ ) and distributed under the terms of the Creative Commons Attribution License, which permits unrestricted use, distribution, and reproduction in any medium, provided the original author and source are credited.

Data Availability Statement: All relevant data are within the paper and its Supporting Information files.

Competing Interests: The Author(s) declare(s) no conflict of interest.

\section{Developing support teachers' digital competencies for an inclusive citizenship}

\section{Lo sviluppo delle competenze digitali degli insegnanti di sostegno per una cittadinanza inclusiva}

\author{
Giuseppa Cappuccio, Giuseppa Compagno \\ University of Palermo \\ E-mail: giuseppa.cappuccio@unipa.it; giuseppa.compagno@unipa.it
}

\begin{abstract}
The present work focuses on the construct of digital citizenship from an educational and inclusive point of view. Considering the general European interest in implementing citizens' digital skills and with particular care for the contemporary situation of overall emergency, due to the Covid 19 pandemic case, the idea is that of considering a possible conceptual link between digital skills and the Capability Approach. In the light of an 'Education for all', the aware development of teachers and, particularly support teachers' digital skills, may be a crucial key to enact inclusive processes able to guarantee any pupil and student the chance to become a capable and valuable citizen, despite his/her frailties and social failures. This paper is part of a wider research project entitled "Best practices and tools of analysis in schools and community contexts: learning, teaching \& inclusion", started in March 2019 and funded by the Department of Psychological, Pedagogical Sciences, Physical Exercise and Training, of the University of Palermo, and of which just a segment related to the analysis of support teachers' digital competence is reported here.
\end{abstract}

Keywords: Capability Approach, citizenship, DigComp, digital skills, inclusive education.

Riassunto. Il presente lavoro è incentrato sulla costruzione della cittadinanza digitale da un punto di vista educativo e inclusivo. Considerando il generale interesse europeo nell'implementare le competenze digitali dei cittadini e guardando, con particolare attenzione, alla situazione emergenziale contemporanea, dovuta alla pandemia da Covid 19, l'idea è quella di intercettare il possibile legame concettuale tra competenze digitali e Capability Approach. Alla luce di una 'Education for all', lo sviluppo consapevole delle competenze digitali degli insegnanti e, segnatamente, degli insegnanti specializzati nelle attività di sostegno, può essere una chiave fondamentale per attuare processi inclusivi in grado di garantire ad ogni allievo la possibilità di diventare un cittadino capace e valente, a dispetto delle fragilità e dei fallimenti sociali. Questo contributo rientra nel più ampio progetto di ricerca intitolato "Best practices and tools of analysis in schools and community contexts: learning, teaching \& inclusion", avviato nel Marzo 2019 e finanziato dal Dipartimento di Scienze Psicologiche, Pedagogiche, dell'Esercizio Fisico e della Formazione, dell'Università degli Studi di Palermo, e di cui qui si riporta solo un segmento relativo all'analisi delle competenze digitali dei docenti di sostegno.

Parole chiave: Capability Approach, cittadinanza, competenze digitali, DigComp, educazione inclusiva. 


\section{INTRODUCTION ${ }^{1}$}

The questions related to digitalization and the rich development of the media request a careful analysis of how important it is to act so as 1) to increase the skills of the person who finds him/herself in a complex and extremely heterogeneous world in terms of needs, characteristics and life prospects; 2) to develop a context that is able to provide training opportunities to teachers, with particular regard to teachers engaged in the field of inclusion and, nowadays, called to a work of communicative and didactic mediation to bridge the many distances exacerbated by the current Covid 19 pandemic emergency.

Due to its intrinsic characteristics, the Capability Approach is a multidimensional approach that can be extended to various reflections in the educational field. Its multi-perspective scope, in which the basic assumption is the relationship between the person with his or her specific connotations, and the training opportunities provided by the context, make this approach a driving force for starting truly inclusive processes. Within this framework, each person is enabled to develop those skills related to the sphere of doing and of being, to freely choose among a set of opportunities promoted by life contexts and society. The expression of one's freedom to act and build has within itself the construction of not only personal, but also social development (Ellerani, 2013).

The development of digital skills, reinterpreted through the Capability Approach, represents an interesting horizon of meaning where to place the challenge that arises in the pedagogical-teaching field in relation to the development of digital skills; this is possible through the link between the theoretical-methodological framework of reference legislation for citizens' digital skills and the meaning offered by the Capability Approach itself.

The guiding hypothesis of the survey here presented is that digital skills, identified through the DigComp model, may help support teachers promote their own agency (Sen 1998, 2001; Nussbaum, 2012; Stoecklin \& Bonvin, 2014) and allow them to modify, rethink and retrain their professional profile along with the promotion of freedom and self-determination for all, without exception.

322 primary and kindergarten support teachers took part in the research during the academic year 2019/2020. The instrument used for the survey is the DigComp 2.1 questionnaire. The data analysis carried out is of a quantitative kind.

\footnotetext{
${ }^{1}$ Giuseppa Cappuccio has written: Introduction, paragraph 2, and paragraph 4.3; Giuseppa Compagno has written: paragraphs 1, 3, 4, 4.1, 4.2, and Conclusions.
}

The present contribution is part of a wider research project entitled "Best practices and tools of analysis in schools and community contexts: learning, teaching \& inclusion", started in March 2019 and funded by the Department of Psychological, Pedagogical Sciences, Physical Exercise and Training, of the University of Palermo, and of which just a segment related to the analysis of support teachers' digital competence is reported here.

\section{THE INCLUSIVE DIMENSION OF THE CAPABILITY APPROACH}

The construct of the Capability Approach was born in the field of economic sciences and social justice and, for its innovative social component, it was largely borrowed in the educational field.

Developed by the philosopher and economist (Nobel Prize, 1998) Amartya Kumar Sen in the 1980s, the Capability Approach constitutes a model of wellbeing and social equality based on what a person can be and can do rather than on what he/she possesses. At the basis of Sen's work, there is the belief that the economic growth of a society is proportional to the capabilities of any individual, or the opportunities to achieve positive results (functioning) through possible choices made through the exercise of personal freedom. In this distinction between the level of capabilities and that of functioning, Sen's model appears in line with the structure of the ICF (International Classification of Diseases) which, while differentiating capabilities and levels of functioning in its classification system, does not contemplate the socio-economic and individual factors which may have an invalidating effect and therefore lead to forms of disability. Vice versa, "The capability approach also has important implications for the analysis of employment issues for persons with disabilities as well as for the analysis of the economic sources and costs of disability" (Mitra, 2006, p. 246).

It goes without saying that the construct of 'capability' is not to be interpreted according to the meaning of the Italian language which calls into question the concept of ability and, above all, associates the ability with the person who possesses it, as a sort of specific attribute. In Sen's vision, on the other hand, 'capacity' derives from the context and takes the form of an opportunity, of a possibility that activates the peculiar resources of the person determining his/her happy development, sheltered from all forms of poverty and deprivation. Precisely in this intuition of the Indian economist the role of an inclusive education culture fits and the person is 
meant to make free choices orienting him/herself among different opportunities on the basis of value criteria and aiming at achieving a state of 'well-being', autonomously and responsibly giving shape to his/her life project. For this to happen, it is not enough for institutions to reformulate their welfare scheme on the person and on his/ her abilities, but it is also necessary that the task of caregivers, parents, educators, teachers, professional trainers is based on an authentic and capable-maker skill (Biggeri \& Bellanca, 2010).

An essential reference point for this contribution is the theoretical framework of the Capability Approach connected to the "implicit pedagogy" of Nussbaum (2012) according to which pedagogy must foster the "flourishing" of people's talents and support "educational processes centred on the global training of the person in terms of critical judgment, open-mindedness, dignity and respect for democratic rights" (Alessandrini, 2014, p. 28).

At the international level, the Capability Approach (Sen, 1985; Nussbaum, 2002) is now considered a new educational and training approach in which the protagonist is the person with his or her set of multiple and much more varied skills than those related to school, work, civil society bodies and political organizations (Sennet, 2012). The Capability Approach is recognized by UNESCO, and since 2002 it has launched a series of initiatives (Education for All) to support various actions, in all countries, aimed at developing and strengthening people's capabilities, underlining, with an inclusive breath, that education is central to this process (UNESCO, 2002, pp. 32-33).

The approach envisages, in fact, a new mapping of education and the acquisition of literacy because once identified the key factors in the development of capabilities (Kuklis, 2005; Saito, 2003; Otto \& Ziegler, 2006), the integral development of each person and rigger a process of awareness is focal.

The 'capabilities' are defined by Sen (2003) as substantial freedoms, a set of opportunities to choose from and the possible combinations of functioning between personal resources and the social, economic and political context. Substantial freedoms are called by Nussbaum 'combined capabilities', i.e. the totality of choice opportunities and possible actions that a person detects in his/her specific personal situation with respect to the life context. These combined capacities require what Nussbaum (2012, p. 29) defines as 'internal capacities', i.e. personal traits, the state of health and tonicity of the body, intellectual and emotional abilities, perception and movement abilities, of internalized teachings, which are able to modify themselves.

\section{THE DIGCOMP MODEL FOR AN INCLUSIVE DIGITAL CITIZENSHIP}

A useful framework for the hypothesis of development of teachers' digital competences aimed at creating an inclusive context for learners, conceived as aware citizens of the $21^{\text {st }}$ century, is the DigComp, i.e. a model for defining the development of digital competence of subjects along their life span, structured in different areas and sub-areas.

In 2005, the JRC-Joint Research Center, a department within the European Commission that provides support to the EU decision-making process through independent scientific advice based on empirical evidence, launched research on learning and digital skills (Carretero, Vuorikari, Punie, 2017). From this research corpus, a tool aimed at improving citizens' digital skills was born: the Reference Framework for the Digital Skills of European citizens, the DigComp, whose most recent version is entitled 'DigComp 2.1' and contains the detailed description of eight levels of mastery of digital competence.

The DigComp framework is divided into 5 dimensions: 1 . areas of skills identified as being part of digital skills; 2 . descriptors of skills and titles relevant to each area; 3. proficiency levels (8) for each skill; 4 . knowledge, skills and attitudes applicable to each competence. 5 . examples of use on the applicability of the competence for different purposes (employment and learning).

The creation of a useful tool to guide teachers and trainers towards digital education arises from the new and rampant need to acquire digital citizenship (Campa, 2019 , p. 148) in order to experience the network that is steeped in risks and that requires the acquisition of new skills useful for learning to safely juggle the rights and duties entailed by the digital universe, in the perspective of a real digital civic education.

The Council Recommendation on key competences for lifelong learning of $22^{\text {nd }}$ May 2018 supports digital competence and reaffirms the right of every person to be educated and trained according to quality and inclusive learning in order to acquire those permanent skills enabling him/her to participate in the life of society.

Already as part of the Europe 2030 Project, the need to invest in education and knowledge as possible ways to emancipate the person was advocated, with a specific focus on the pursuit of excellence and the development of skills, in a possible and perfectible vision of improvement of the condition of citizens without excluding anyone.

In other words, over time there is a need to develop not only digital skills, suitable for the development of 
new technologies, but also the need to implement digital inclusion so that the risk of the digital divide is neutralized. This term refers to a new form of inequality that can materialize in a social inequality between those who have access to the internet and, therefore, have more professional and educational opportunities and those who do not have easy access to the opportunities of the web or do not have it at all (Lupac, 2018).

\section{INCLUSION BETWEEN DIGITAL KNOWLEDGE AND CAPABILITIES DEVELOPMENT}

Developing a parallel reflection on the reference framework for digital skills and the Capability approach, there are some overlapping lines of development. These include the enhancement of ongoing training that makes it possible to integrate and develop harmoniously with the changing and fluid characteristics of contemporary society; yet, training is generated starting from partly innate peculiarities, but mostly favoured by the context in which they develop. Hence, the need for an active and continuous commitment on the part of the economic and political decision makers so that the theoretical systems outlined are concretely implemented.

Assuming the perspective of the Capability Approach, it is possible to affirm that the well-being of a nation is measured on the base of the standards it aims to achieve; in terms of digital skills, the desirable standard is the achievement of digital citizenship. The standard is measured through the functioning or on the base of the possibility of being, doing and participating of people; critical participation, creative construction and awareness of the new digitized reality is the functioning that makes welfare possible for all.

Freedom and well-being are another characterizing element. There is freedom to choose well-being when the aspects that have to do with being, doing and participating are efficiently realized. This element must be measured on the base of capabilities; as the fruit of both innate dispositions and of the educational, social, cultural, political and economic context, these capabilities are the measurable descriptors that allow us to understand the level of skills acquired. Here, again, we may find another noteworthy parallelism: Nussbaum (2020, p. 223) affirms, several times, that her thesis is based on the concept of dignity (coinciding with ability) and that "it may be found in a large number of variants"; that is why it is necessary to examine several levels of reason that include different knowledge, skills and attitudes.

If this second element represents the sphere within which the political-social action must and can be inci- sive, the last element to be submitted to the lens that intends to validate the relationship between the Capability Approach and digital skills, instead concerns the personal sphere and specifically personal mobilization. This element is measured in terms of agency, meant as the development of the freedom needed to make choices, to formulate and pursue one's goals; this sphere could coincide with dimension 4 of DigComp which contemplates the knowledge, skills and attitudes of the person aimed at influencing the action.

The activation of the agency is what must be aimed at so that there is a growth in freedom and the critical ability to make choices between different options (Sen, 2000; Nussbaum, 2012). The definition of the objectives involves the design and construction of the action to make them operational; the activation of opportunities and available resources complete the action (Urbani, 2016). On the other hand, there is no digital competence if there is not the development of a critical capacity and conscious choice, based on targeted actions that aspire to the formation of digital citizenship. This term indicates the set of rights and duties that can simplify the relationship between citizens, business and public administration through digital technologies.

\section{THE ENQUIRY}

As far as the theoretical framework previously outlined, during the A.Y. 2019/2020, a survey was carried out in the provinces of Palermo, Agrigento, Caltanissetta, Enna and Trapani focusing on the detection of the five areas of digital competence identified in the DigComp model.

They are:

1. Information and Data Literacy

2. Communication and Collaboration

3. Content-Creation

4. Safety

5. Problem-Solving.

The DigComp 2.1 structured questionnaire was used to survey the exposed areas. It was built in accordance with the methodology outlined for the delineation of citizens' digital skills.

The purpose of the survey was the detection of the areas forming the digital competence owned by support teachers of primary and kindergarten schools, areas necessary to promote inclusion especially in Covid time; in addition, through the correlation assessments between the various items in the different areas, the reliability and validity of the tool used was assessed. 


\subsection{Target}

322 Sicilian primary and kindergarten school support teachers participated in the survey. The sample was selected taking into consideration the following variables: age, sex, educational qualifications and years of service. Analysing the sample, in relation to the age possessed, it is possible to state that (Graph 1): $62 \%$ are between 36 and 50 years old; $29 \%$ are between 21 and 35 years old and $9 \%$ are between 51 and 62 years old.

The sample is composed of $91 \%$ of women and $9 \%$ of men. In-service support teachers were interviewed in the provinces of Palermo, Agrigento, Caltanissetta, Enna and Trapani as shown in Graph 2:

The recipients of the survey can be grouped on the base of the qualification held in four categories:

- secondary school diploma: $68.7 \%$ of the participants;

- university degree: $27.3 \%$ of the participants;

- PhD: $1 \%$ of the participants;

- first or second level university master degree course: $3 \%$ of the participants.

$61 \%$ of support teachers have between 18 and 21

\section{SUPPORT TEACHERS' AGE}

In aged $21-35$ an aged $36-50$ =aged $51-62$

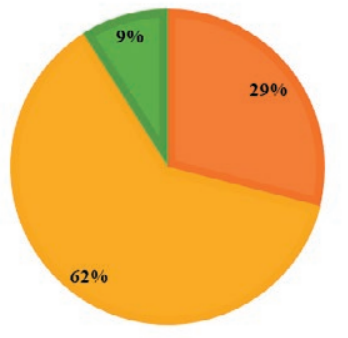

Graph 1. Support teachers' age.

\section{City/Town of origin}

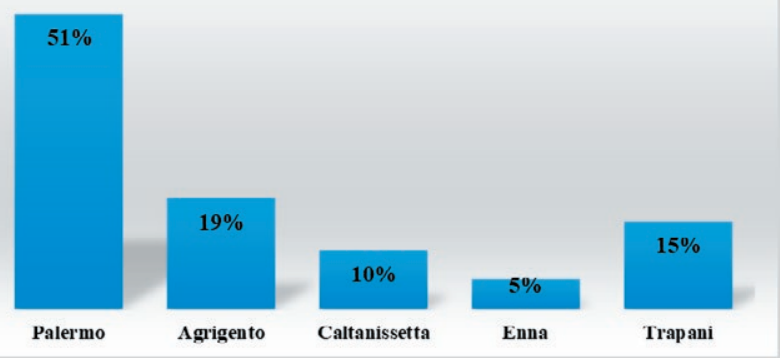

Graph 2. City/town of teachers' origin. years of service, $17 \% 15$ years, $8 \%$ between 14 and 5 years and $4 \%$ less than 5 years.

Although the variety of qualifications they had, they all attended the Ministerial Specialization course for Support Teachers held by the University of Palermo which included 75 hours training on the use of technologies for inclusive education. During the ICT inclusive classes teachers got acquainted with teaching methodologies in order to use digital technologies to support didactic inclusion according to the different profile of pupils with cognitive-intellective disabilities, motor disabilities or sensory-perceptive disabilities.

\subsection{The DigComp 2.1 questionnaire}

The European Commission suggested that digital literacy is "increasingly becoming an essential life competence and the inability to access or use ICT has effectively become a barrier to social integration and personal development" (European Commission, 2008, p. 4).

The DigComp 2.1 questionnaire is composed of forty-five items divided into 5 areas of digital competence summarized as follows:

1. information e data literacy (7 item)

2. Communication and collaboration (13 item)

3. Content-creation (5 item)

4. Safety (11 item)

5. Problem-solving (9 item).

Areas 1, 2 and 3 are rather linear while areas 4 and 5 are more transversal. This means that while areas 1 to 3 deal with competences that can be re-traced in terms of specific activities and uses, areas 4 and 5 apply to any type of activity that is been carried out through digital means. This does not mean that areas 1,2 , and 3 are not inter-related. Although each area has its own specificity, there are several forced overlapping points and cross-references to other areas. At this point, we need to discuss "Problem solving" (area 5), competence area which is the most transversal of all. In the framework, it is a standalone competence area, but on the other hand elements of problem solving can be found in all competence areas. For instance, the competence area "Information" (area 1) includes the competence "evaluating information", which is part of the cognitive dimension in problem solving. Communication and content creation include several elements of problem solving (namely: interacting, collaborating, developing content, integrating and re-elaborating, programming, etc.). Despite including problem-solving elements in relevant competence areas, it was considered as necessary to have a dedicated standalone area about problem solving, as for the relevance this aspect has on the appropriation of technologies and 
digital practices. It can be noticed that some of the competences listed in areas 1 to 4 can also be mapped into area 5.

The DigComp, in the original version, consists of multiple-choice questions divided into 8 levels; however, following a sample administration of the questionnaire, it emerged that the participants tended to remain on the range of intermediate responses, making the answers insignificant. Therefore, we proceeded to restructure the response levels by moving to a five-level configuration, mixing and simplifying those options that sometimes seemed repetitive and similar to each other:

- level 1 (with a guide);

- level 2 (independently or with a guide only when necessary and solving simple problems);

- level 3 (autonomously and also guiding others in solving well-defined and non-ordinary problems);

- level 4 (at advanced level, in accordance with my personal needs and those of others and in complex contexts);

- level 5 (at a highly advanced and specialized level).

As to the administration of the questionnaire, the Google Modules platform was used and the administration was divided into two phases: the first one took place in March 2020 with in service teachers of the schools in the areas of Palermo, Agrigento, Caltanissetta, Enna and Trapani while the second one took place in June 2020.

\subsection{Results}

The data collected through the administration of the DigComp 2.1 Questionnaire can be analysed by dividing the five areas investigated. The analysis was carried out with the aid of IBM SPSS v23 statistical analysis software. The identification of the means and frequencies obtained from the sample allowed us to evaluate the digital skills of the reference sample.

The average scores obtained within the different areas of digital competence are analysed below. The scores for each area are positioned around the central value (3) without macroscopic deviations from this value. The items showing an average score value greater than 3.4 are items 16 (I can identify the appropriate means of communication for a given context), 17 (I can recognize appropriate digital technologies for sharing data, information and digital content), 22 (I can choose the communication methods and strategies suitable for a specific audience), 25 (I can recognize the data that I produce through digital tools, environments and services). On the other hand, those that scored less than 2.9 are the items (I can identify the copyright rules and licenses that apply to data, information and digital content),
31 (I can list the instructions for a computer system at purpose of solving a problem or performing a task), 43 (I can identify technical problems when using digital devices and environments) and 44 (I can identify solutions to solve them).

The analysis of the Standard Deviation (represented by the symbol $\sigma$ which shows how much variation or dispersion exists from the average) detects deviations in the order of the unit: items 26 (I can recognize the data I produce through digital tools, environments and services), 30, 31, 33 (I can differentiate risks and threats in digital environments) and 44, are those that have obtained a more marked standard deviation, between 1.3 and 1.4, indicating that the answers obtained are positioned, more than the other items, towards the extremes (level 1-level 5). Items 30, 31 and 44 obtained the lowest average score, this suggests that they are those in which the participants responded with level 1 and therefore show a lack in this specific aspect.

From the analysis of the specific frequencies for each area of digital competence (diagrammed in graph 3) it emerged that Level 1 is infrequent in all areas. In areas of competence 5 and 3 the responses in level 1 were slightly higher than $5.5 \%$, while in the other areas the frequency was lower.

The frequency of Level 2 appears to be almost balanced between all areas; areas of competence 3 and 5 stand out with a value of $33 \%$.

Level 3, being the intermediate one, is balanced between all areas of competence with a value equal to $25.9 \%$. Level 4 is significantly higher in the area of competence 2 with a frequency of $32 \%$.

Finally, Level 5, despite being an extreme level, shows considerable frequencies with percentages above $11 \%$ and a peak in area 4 of $15.5 \%$.

\section{4 correlation analysis}

The data obtained through the administration of the DigComp 2.1 questionnaire were imported into the IBM SPSS v23 data analysis software, in order to carry out

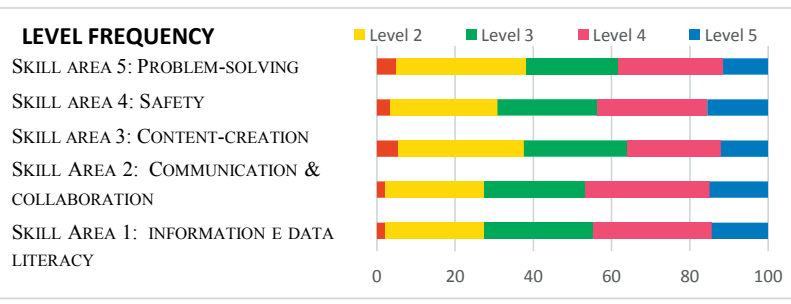

Graph 3. Level frequency according to competence areas. 
Table 1. Matrix of bivariate correlations by areas of competence.

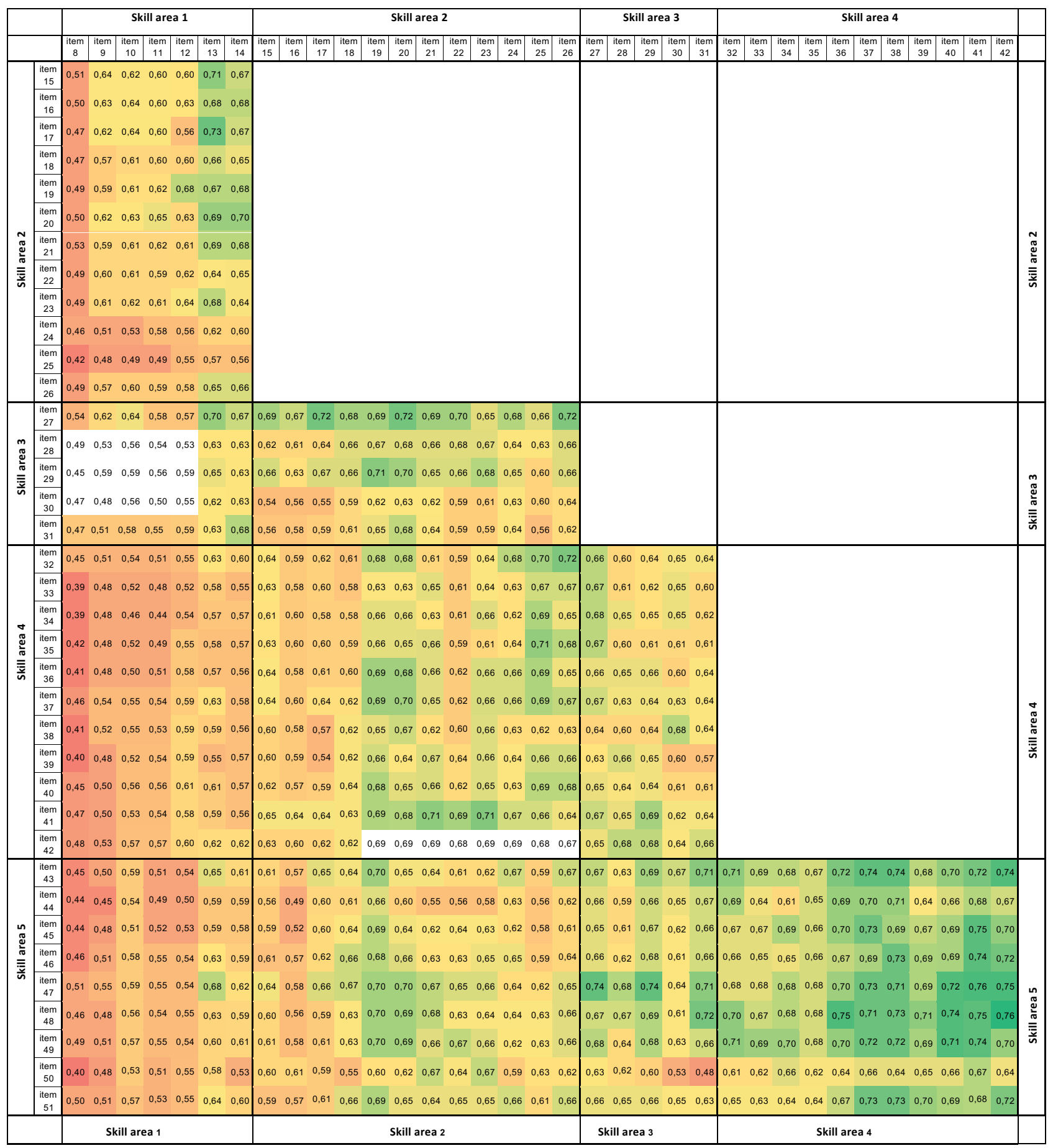

a correlation analysis. The bivariate correlation analysis between all items was carried out on the data, using the Pearson model, which identifies the intensity of the dependence between the combinations of the various items. The resulting matrix, transferred to Excel, was reworked by removing the specular part, dividing it by areas of digital competence and inserting conditional formatting (for colour scale: "green" = higher values, "red" = lower values) in order to highlight correlations between the areas themselves (See Table 1). 
Analysing the matrix, it is observed that the strongest correlations are concentrated between the 4vs5 area of competence (with an average of 0.69). Following, decreasing correlation coefficients, are the 3vs5 areas of competence (in which an average of 0.65 is recorded); $3 \mathrm{vs} 2$, 3vs4 and 4vs2 (with averages equal to 0.64 ); $2 \mathrm{vs} 5$ (with an average of 0.63 ); 1vs2 (in which we record an average of 0.60 ); 1vs3 (with an average of 0.57 ); 1vs5 (with an average of 0.54 ) and finally lvs4 (in which an average of 0.53 is recorded). It also emerges that items 8 , 9, 10, 11 and 12 appear having lower item-test correlations.

\section{CONCLUSION}

Digital skills are required and therefore can be used in the workplace, at school and in every aspect of everyday life. They affect all stages of life: from infancy to old age. For these reasons, the European legislation considers the issue of digital competence as essential for the places dedicated to the training of the person. Influenced by the changes brought about by the advent of New Media and web 2.0, digital competence is now in demand both from the student and from the teacher. Just think of the introduction of digitized platforms (such as the electronic register, for example) that allow interaction between students, teachers and parents. Last but not least, in time of Covid 19, the emergent advent of digital platforms aimed at the sudden transition from face-to-face teaching to distance learning have made digital skills a 'must have' for all teachers, especially those working on support activities called to find new, creative ways to shorten the learning distance and to mediate knowledge to benefit pupils with special educational needs.

The survey conducted confirms a good degree of correlation between most of the areas. Only area 1 is less correlated with the others. The analysis establishes a good level of generalized digital competence, this indicates the wide spectrum of digital operations used in the various fields of everyday life. However, in relation to the area of digital content creation and problem solving (area 3 and area 5), there is a significant change in the trend towards greater difficulties in complying with activities related to these areas of expertise. Therefore, it is possible to affirm that the critical re-reading of digital competences, here presented in the light of the Capability Approach, promotes a pedagogical reflection aimed at developing the areas that make the person capable of responding to the challenges and complexity that the "Digital Era" requires in a creative, proactive, innovative and inclusive way.

\section{REFERENCES}

Alessandrini G. (Ed.). (2014). La "pedagogia" di Martha Nussbaum. Approccio alle capacità e sfide educative. Milano: FrancoAngeli.

Biggeri, M., \& Bellanca, N. (2010). Dalla relazione di cura alla relazione di prossimità: l'approccio delle capability alle persone con disabilità. Dalla relazione di cura alla relazione di prossimità. Napoli: Liguori Editore. 7-200.

Campa, S. (2019). Le competenze di cittadinanza digitale. Quadri di riferimento, lessico e risorse. Idee in form@ zione, 147-168. DOI 10.4399/97888255202627

Carretero, S., Vuorikari, R., Punie, Y. (2017). DigComp $2.1 \mathrm{Il}$ quadro di riferimento per le competenze digitali dei cittadini Con otto livelli di padronanza ed esempi di utilizzo.

Ellerani, P. (2013). Gli scenari educativi e formativi internazionali in mutamento: contesti cooperativi e capability approach. Formazione e Insegnamento, XI, 4, 17-31. doi: 10746/-fei-XI-03-13 0

Kuklis, W. (2005). Amartya Sen's Capability Approach. Theoretical insights and empirical application. NYLondon: Springer.

Lupac, P., (2018). Beyond the digital divide. Contextualizing the information society. Bingley: Emerald Publishing.

Mitra, S. (2006). The capability approach and disability. Journal of disability policy studies, 16(4), 236-247. https://doi.org/10.1177/10442073060160040501

Nussbaum, M. (2020). La tradizione cosmopolita. Un ideale nobile ma imperfetto, Milano: Bocconi Editore.

Nussbaum, M. (2012). Creare capacità. Bologna: Il Mulino.

Nussbaum, M. (2002). Capabilities and social justice. International Studies Review, 4(2), 123-135. https://doi.org/10.1111/1521-9488.00258

Otto, H.U., Ziegler, H. (2006). Education and capabilities. $S W$ \& $S, 4-2,269-287$. http://nbn-resolving.de/ urn:nbn:de:0009-11-7545

Saito, M. (2003). Amartya Sen's Capability approach to Education: A critical exploration. Journal of Philosophy of Education, 1, 17-33. https://doi. org/10.1111/1467-9752.3701002

Sen, A. (1985). Commodities and Capabilities. Amsterdam: North Holland.

Sen, A. (1998). Mortality as an Indicator of Economic Success and Failure. The Economic Journal, 108 (446), 1-25. https://doi.org/10.1111/1468-0297.00270

Sen, A. (2000). Lo sviluppo è libertà. Perché non cè crescita senza democrazia. Milano: Mondadori.

Sen, A. (2001). Economic development and capability expansion in historical perspective. Pacific Economic 
Review, 6(2), 179-191. https://doi.org/10.1111/14680106.00126

Sen, A. (2003). Development as Capability Expansion. In S. Fukuda-Parr et Alii. Readings in Human Development. New Delhi and New York: Oxford University Press.

Sennett, R. (2012). Together: The rituals, pleasures and politics of cooperation. Yale: University Press.

Stoecklin, D., Bonvin, J.M., (2014). Children's Rights and the Capability Approach. Challenges and Prospects. NY-London: Springer.

UNESCO (2002). Education for All: is the world on track? Paris, France: UNESCO Publishing. Retrieved from http://hdl.voced.edu.au/10707/46735

Urbani, C. (2016). La capacitazione dello sviluppo professionale docente: oltre il valore della competenza. Tesi di dottorato, Università Ca Foscari, Venezia.

European Commission (2008). Digital Literacy European Commission working paper and recommendations from Digital Literacy High-Level Expert Group. Brussels, Belgium: Author. Retrieved from http://www. ifap.ru/library/book386.pdf. 